\title{
ACOSO SEXUAL EN LA NOVELA TESTIMONIAL SOBRE EL "CASO NEVENKA" DE JUAN JOSÉ MILLÁS ${ }^{1}$
}

\author{
Milica Lilic ${ }^{2}$
}

Acoso sexual en la novela testimonial sobre el "caso Nevenka" de Juan José Millás

Resumen: El acoso sexual, ya sea provocado por satisfacer la necesidad del dominio o simplemente por conseguir un fin sexual, es una conducta indeseada y humillante que atenta contra la dignidad de la víctima y deja consecuencias en su estado físico, psicológico y emocional, así como en sus relaciones interpersonales y en la esfera profesional. Sus rasgos se analizan en la novela testimonial sobre el "caso Nevenka" de Juan José Millas, donde el autor hace hincapié en el fenómeno de la criminalización de la víctima, concluyendo que el concepto sociocultural actual permite que el acoso se desarrolle porque se tolera.

Palabras clave: acoso sexual, el "caso Nevenka", Juan José Millás, criminalización de la víctima, novela testimonial actual

\section{Sexual Harassment in the Testimonial Novel about the "Nevenka Case" by Juan José Millás}

Abstract: Sexual harassment, whether provoked by satisfying the need for domination or by simply achieving a sexual goal, is an unwanted and humiliating behavior that threatens the victim's dignity and leaves consequences on their physical, psychological and emotional condition, as well as on their interpersonal relationships and the professional sphere. Its features are analyzed in the testimonial novel about the "Nevenka case", written by Juan José Millas, where the author emphasizes the phenomenon of the criminalization of the victim, concluding that the current sociocultural concept allows for the harassment to be developed just by tolerating it.

Key words: sexual harassment, the "Nevenka case", Juan José Millás, criminalization of the victim, current testimonial novel

\section{Concepto y características del acoso sexual}

Aunque el acoso sexual tiene sus propios elementos característicos y cuenta con un contexto y repercusiones negativas particulares, al igual que el mobbing, implica la humillación y atenta contra la dignidad de la persona afectada. José Luis González de Rivera encuentra las dinámicas de ambos tipos de acoso muy similares, ya que en

\footnotetext{
${ }^{1}$ Fecha de recepción: 05/03/2018.

Fecha de aceptación: 06/12/2018. ${ }^{2}$ Investigadora predoctoral en Lenguas, Textos y Contextos, Universidad de Granada; milicalilic@correo.ugr.es.
} 
muchos casos "la sexualidad, más que un fin en sí misma, es utilizada como medio, instrumento, o pretexto para ejercer control, puesta al servicio del poder y no al del placer" (2002: 117).

Siempre es una conducta no deseada y ofensiva de naturaleza sexual, que crea un entorno laboral humillante, degradante e intimidatorio para la persona que es objeto de la misma. Su desarrollo depende de distintos factores y variables de carácter social, histórico y psicológico. Los de mayor impacto se basan en las creencias populares y en la postura que la sociedad ha mantenido sobre la mujer a lo largo de la historia. Así, el papel dominador del hombre sobre la mujer y los estereotipos de género femenino son causas principales del acoso sexual. González de Rivera afirma que "la negación de la cualidad humana a la mujer es la base de todos los abusos y todos los acosos sexuales" (2002: 118). Incluso las propias víctimas, apoyadas en dichos estereotipos, pueden fomentar su desarrollo y convertirse en cómplices de su propio acoso, presentando un gran nivel de tolerancia y justificando la conducta de su acosador.

Esto quiere decir que el acoso sexual se relaciona principalmente con el predominio de una cultura masculina en la organización, especialmente en puestos directivos, esto es, que se inscribe en tres ejes principales: "la violencia contra las mujeres, un entorno laboral sexista y un marco de abuso de poder (tanto jerárquico como de género)" (INMARK 2006: 4). Su desarrollo está condicionado también por unos factores y prácticas que se cultivan dentro de la organización: la falta de normas laborales claramente establecidas, la falta de ética y la precariedad laboral.

Habitualmente se distinguen dos tipos básicos de acoso sexual, dependiendo de si conllevan un determinado chantaje o no (Moreno Jiménez y Báez León 2010: 38). El 
primero, conocido como quid pro quo, consiste en solicitar favores sexuales por parte del acosador, ya sea implícita o explícitamente, a cambio de ofrecer algunos beneficios laborales (continuidad del contrato laboral, promoción profesional, cambios en el salario, etc.) o no perjudicar laboralmente a la víctima despidiéndola o haciendo que sufra otro tipo de consecuencias desagradables (cambio del puesto de trabajo, reducción del sueldo, peores condiciones laborales, etc.). Por su naturaleza, este tipo del acoso sexual se suele ejercer "sobre las trabajadoras con mayor precariedad laboral" (Díaz Descalzo 2003: 182), mientras que los agentes que lo ejercen suelen ser los que tienen el poder de tomar decisiones y ocupan un cargo superior al de la víctima. Es decir, se trata del abuso de poder basado en amenazas como estrategia para requerir favores de tipo sexual. Según González de Rivera (2002: 124), este tipo de requerimientos puede ser provocado por dos motivos: la consecución de un fin sexual (donde el sexo es la finalidad y el acoso un instrumento) y la intimidación y agresión a través del acoso sexual como instrumento preferente (donde el acoso es la finalidad y el sexo un instrumento).

Por otra parte, está el acoso sexual producido por un ambiente hostil donde las mujeres reciben un trato discriminatorio, o bien, donde las condiciones de trabajo implican la exhibición de sus atributos sexuales (como puede ser la vestimenta), aunque el trabajo no sea de tipo sexual. De esta manera la imagen de la mujer se reduce a un objeto sexual, sometido a la voluntad de los hombres. De igual forma, este tipo de acoso sobreentiende gestos, palabras o escritos de naturaleza sexual que se pueden considerar ofensivos, así como alusiones o comentarios groseros y degradantes basados en el sexo o sobre la vida íntima de la víctima. Tienen lugar, a menudo, en presencia de otras personas, por lo que se intentan plasmar como una realidad en cuanto a las relaciones 
entre hombres y mujeres en el mundo laboral. Tal ambiente laboral afecta el razonamiento de las mujeres, que pueden considerarse responsables de haber provocado tal comportamiento de sus superiores o compañeros de trabajo. Incluso la propia organización y la sociedad tienden a basarse en los patrones de conducta y los roles de cada sexo, justificando ese comportamiento de los hombres y considerando que las mujeres tienen una obligación y responsabilidad de poner un límite, "sin que en ningún caso consideren que son ellos [los hombres] los principales responsables y a quienes hay que exigir una modificación de conductas" (Almany Gómez et al 2001: 176).

Cabe resaltar, sin embargo, que el acoso sexual contiene un elevado componente de subjetividad, por lo que esta clasificación queda limitada por la percepción y la sensibilidad de cada víctima. Esto quiere decir que se trata que un concepto subjetivo, ya que cada persona determina qué conductas acepta y tolera y cuáles le resultan molestas. Es decir, no es posible crear un catálogo de comportamientos estandarizados susceptibles de ser considerados acoso sexual. Éstos dependen de los criterios del receptor, independientemente de la intencionalidad del emisor, de manera que "una conducta determinada no es ofensiva intrínsecamente, lo es en la medida que genera molestia para quien la recibe" (Pérez Guardo 2012: 206). Esto quiere decir que el acoso sexual se produce solamente en situaciones cuando la visión de la sexualidad es unilateral, esto es, cuando los comportamientos del agente son mal recibidos, no deseados y ofensivos, y cuando ocurren de forma frecuente y repetitiva, afectando el estado psicológico y emocional de la víctima. De ahí que toda una serie de percepciones individuales y colectivas afecta la interpretación de las manifestaciones de acoso y su efecto en la persona agredida, de manera que "una misma situación no tiene el mismo significado según quién la protagonice, el contexto en el que se ejerza y la situación 
laboral y personal de la mujer a la que va dirigida" (Alemany Gómez et al 2001: 206). En contrapartida, todo comportamiento sexual conscientemente consentido por el receptor, aunque implique acciones más explícitas y es socialmente inadecuado, no puede interpretarse como acoso sexual.

Sin embargo, es importante señalar aquí que las propias mujeres tienden a minimizar los hechos e incluir bajo el concepto del acoso sexual solamente las conductas más graves, esto es, comportamientos que implican agresiones físicas o propuestas no deseadas de naturaleza sexual (Alemany Gómez et al 2001: 176). Es decir, suelen aguantar los comentarios y las acciones de naturaleza sexual que les molestan, les incomodan e incluso les avergüenzan, interpretándolas como típicas de relaciones entre hombres y mujeres o aceptándolas como situaciones inherentes a su condición de mujer. De igual forma, algunos hombres no identifican $-\mathrm{o}$ no quieren identificar- esas conductas como inapropiadas, sino que las disimulan a través de calificativos como piropos, juegos o bromas.

El concepto del acoso sexual empezó a desarrollarse en los años setenta, especialmente en los Estados Unidos, con la aparición de los movimientos feministas que exigían sus derechos civiles. El término sexual harrassment, lanzado por primera vez por las feministas de la Universidad de Cornell de Nueva York, se generalizó en todos los países anglosajones a partir de 1975. Fue la Jurisprudencia Estadounidense, concretamente la Comisión para la Igualdad de Oportunidades en el Empleo (EEOC Equal Employment Opportunity Commission) la primera en establecer oficialmente las directrices para el acoso sexual en el año 1980, definiéndolo de la siguiente manera: 
Unwelcome sexual advances, requests for sexual favors, and other verbal or physical conduct of a sexual nature when:

- Submission to such conduct is made either explicitly or implicitly a term or condition of an individual's employment, or

- Submission to or rejection of such conduct by an individual is used as a basis for employment decisions affecting such individual, or

- Such conduct has the purpose or effect of unreasonably interfering with an individual's work performance or creating an intimidating, hostile, or offensive working environment. (Equal Employment Opportunity Commission, Title 29, part 1604.11)

En cuanto a la legislación española, desde el año 1996, y con últimas modificaciones en 2004, el Código Penal hace referencia expresa al acoso sexual, distinguiendo dos posibles escenarios: donde el actor del delito solicita favores sexuales en el ámbito laboral provocando a la víctima una situación gravemente intimidatoria y donde el culpable del acoso sexual comete el hecho prevaliéndose de su posición de superioridad laboral (Ley 10/1995 art. 184). En ambos casos el castigo aumenta si la víctima es especialmente vulnerable, por motivo de su edad, situación o enfermedad, siendo el más alto la pena de prisión de seis meses a un año.

No obstante, a pesar de las normativas establecidas y los datos estadísticos que lo testifiquen, todavía existe una escasa transparencia en cuestión del tema en España. Las cifras existentes normalmente hacen alusión sólo a los casos denunciados, no a los acaecidos, lo que dificulta la visibilidad y la objetivación del fenómeno. Aparte de tratarse de conductas que afectan los aspectos más íntimos y personales de las víctimas que las sufren, se presentan otras razones adicionales susceptibles de inhibir una denuncia: "el temor a represalias, la desconfianza de la utilidad de la denuncia, la 
normalización de gran parte de estas conductas, la voluntad de olvidarlo, etcétera" (Pérez Guardo 2012: 209).

Uno de los primeros casos con sentencia condenatoria registrados en el juzgado español ocurrió en marzo de 2001, cuando Nevenka Fernández, una joven de 26 años, después de estar meses sufriendo el acoso sexual, dimitió públicamente de su cargo de concejala de Hacienda y Comercio del Ayuntamiento de Ponferrada, y denunció en una rueda de prensa al entonces alcalde, Ismael Álvarez. La importancia que ha cobrado el “caso Nevenka"3 en la sociedad española queda reflejada en su manifestación en la literatura a través de la novela testimonial Hay algo que no es como me dicen. El caso de Nevenka Fernández contra la realidad (2004), escrita por Juan José Millás.

\section{El papel del autor en la novela sobre el "caso Nevenka"}

La obra principalmente trata un tema social colectivo, pero relata una historia individual. Esto es, narra de un caso concreto, pero apela a todo un colectivo de mujeres víctimas del acoso en el ámbito laboral. Es una historia sobre hechos reales, relatada en primera persona y desde el punto de vista de la víctima de aquellos sucesos, por lo que pertenece al género de la novela testimonial.

Debido a la confusión que se produce por la afinidad de la novela testimonial con otras formas, en muchas ocasiones se ha explicado erróneamente "por lo que él no es,

\footnotetext{
${ }^{3}$ Cuando un caso del acoso se vuelve público o al menos conocido entre los niveles superiores de la empresa, se suele denominar "caso de X", siendo "X" siempre la víctima y no el agresor. De esta forma, aún sin llegar a culpabilizar a la víctima, se tiende a exponer su nombre en primer plano (Piñuel y Zabala 2001: 67).
} 
por su grado de semejanza con el periodismo o con la novela ficcional y no se piensa su singularidad ni su propuesta en tanto discursivo nuevo" (Amar Sánchez 1992: 14). Partiendo de este postulado, habría que cuestionar su interpretación como "un género impuro", ya que este nombre se le ha atribuido precisamente por su carácter ambiguo que no permite determinar si es literatura (no es un texto puramente imaginario) o periodismo (no cumple con su función informativa presentada desde una distancia objetiva). En ese sentido y con el fin de señalar la singularidad del género, Ana María Amar Sánchez destaca un elemento en particular que determina su posición intersticial, esto es, que comprueba que no pertenece a ninguno de los géneros citados, sino que ocupa su propio espacio entre los géneros literarios: la subjetivización (1990: 449). Se caracteriza por narrativizar o ficcionalizar las figuras provenientes del mundo real, convirtiéndolas en personajes y narradores, de manera que, así de subjetivizados, pertenecen a ambos espacios, tanto al real como al narrativo. Es decir, los implicados se narrativizan y se convierten en personajes, pero no dejan de pertenecer al mundo real y ser los que tomaron parte en los acontecimientos reales. Es justamente ese doble carácter de los elementos que construyen a esos personajes el que genera la ruptura entre la realidad y la ficción. Así, frente al distanciamiento general de otras formas de narración, especialmente el periodismo o la historia, que optan por una perspectiva alejada, la novela de no-ficción, como la denomina la autora, respeta la base real, pero destaca momentos clave, trabaja minuciosamente los fragmentos, personajes y detalles, de tal forma que afectan toda la acción, creando una realidad alternativa y ficcionalizando la historia real.

Dichos rasgos de la novela testimonial se observan en la obra sobre el "caso Nevenka", ya que el autor hace pública la versión de la protagonista de aquellos sucesos 
mediante su escritura. Elige qué parte de esa intrahistoria extraer del anonimato y cuestiona la verdad absoluta de la historia, desmintiendo de esa forma su versión oficial, manipulada por las autoridades y la prensa. Así, reconstruye la realidad a través de la investigación y un proceso determinado de recolectar y ordenar la información, por lo que su discurso tiene una dimensión argumentativa. Esa investigación queda representada por las confesiones de Nevenka grabadas en el magnetofón. Éstas presentan el material fijo de una novela testimonial que no puede ser modificado por exigencias de la obra, pero la forma en la que el autor las utiliza para crear la historia sufre transformaciones, de manera que no representan un mero reflejo de la realidad, sino que construyen una nueva realidad, o mejor dicho, una representación de esa nueva realidad "con la que se denuncia la "verosimilitud" de otras versiones" (Amar Sánchez 1990: 447)

La necesidad de Millás de escribir la historia de Nevenka incluso queda reflejada dentro del libro, donde el narrador homodiegético Juanjo -que lleva el mismo nombre, aunque incompleto que el autor-, explica cómo fue desarrollándose su interés por el caso y el proceso de la creación de la obra. La presencia de estos ecos autobiográficos fomenta la credibilidad y legitimidad de la narración. Asimismo, Millás establece el contacto con los lectores, les hace preguntas y les invita a opinar sobre los sucesos, provocando sentimientos de solidaridad y empatía.

Finalmente, con el propósito de destacar su implicación real en lo ocurrido en la novela, Millás hace sentir su presencia, toma partido, participa activamente y empatiza de manera constante con la protagonista: "se entiende que la intención de recordar y hacer presentes en el discurso sobre el pasado a aquellos cuya voz fue negada por su 
condición de víctimas o perdedores responde a un imperativo moral" (Sánchez Zapatero 2011: 395), de manera que su obra cumple una función ética.

\section{Los antecedentes en el "caso Nevenka"}

Millás procura reconstruir el pasado de su protagonista y establecer relaciones lógicas, que luego permitirán una cohesión entre su personalidad y el acoso sufrido. Así, observa que el acoso sexual fue simplemente el resultado de una serie de acontecimientos y situaciones que acompañaron a Nevenka desde su niñez y afectaron el desarrollo de su personalidad, convirtiéndola en una joven bien educada y obediente. Son precisamente la inocencia, la dependencia afectiva y la autenticidad las características dominantes en personas con mayor riesgo de sufrir acoso (González de Rivera 2002: 86). La inocencia de Nevenka y su necesidad de autorealizarse, incluso sacrificando su propia comodidad y seguridad, provienen de dos marcas complicadas que lleva desde el nacimiento y que la hicieron diferente: su nombre de procedencia rusa y el hecho de haber sido concebida fuera de matrimonio, dato escandaloso en Ponferrada de los años 70. Insistiendo en la marginación involuntaria de Nevenka, el autor "acentúa la dimensión patética del personaje y solicita la compasión del lector" (Fauquet 2011: 263).

La dependencia afectiva, esto es, la tendencia a conservar las relaciones interpersonales, la necesidad de recibir la afirmación y el apoyo de los demás y la hipersensibilidad al rechazo, se relacionan directamente con la figura del padre de Nevenka. Ella hacía solo las cosas que él aprobaba y constantemente se empeñaba en 
demostrarle que valía. Como ella misma lo admite, "el reconocimiento de mi padre siempre ha sido muy importante para mí" (Millás 2013: 112). Millás encuentra una simetría evidente entre estos dos personajes: "Me encontraba, en fin, frente a la hija de un empresario que había estudiado Empresariales; la hija de un karateka que había sido campeona nacional de judo; la hija de un individuo convencional, que había sido convencional hasta el paroxismo" (Millás 2013: 114). Debido a tanta influencia de la figura paterna y a su necesidad patológica de asegurarse de que la querían, Nevenka terminó entregándose a un hombre de la edad de su padre, quien más tarde se convertiría en su acosador.

\section{La metamorfosis del personaje de Nevenka: de una niña ejemplar a una mujer rebelde}

El personaje de Nevenka corresponde al concepto de la "víctima inocente", que Philippe Hamon (1984: 190) explica considerando dos ejes distintos: el eje moral, donde se oponen el inocente y el culpable; y el eje narrativo, constituido por la pareja víctima-vencedor. En el eje moral, se crea un vínculo de simpatía entre el inocente, que es el personaje positivo, y el lector. Por otra parte, en el eje narrativo, el vencedor es el que triunfa en la historia, por lo que Nevenka desempeña sucesivamente ambos papeles. Desde el estatus de víctima, donde se enfrenta al acosador como vencedor en una situación de acoso sexual, pasa a superar el trauma, ganar el juicio y rehacer su vida, hecho que la convierte en la triunfadora. 
Basándose en los estudios de György Lukács, Fauquet compara el personaje de Nevenka con uno heroico y señala que "el héroe de toda novela sufre dos transformaciones: la primera lo hace pasar de la ignorancia al conocimiento de sí mismo; y la segunda lo lleva de la pasividad a la acción" (2011: 263). En ese sentido, el proceso de lucidez en Nevenka es progresivo y permite que el lector pase la misma trayectoria que la víctima, desde la ingenuidad hasta el saber.

Así, antes de vivir esa experiencia traumática, Nevenka asociaba el término "acoso" con las mujeres incapaces de defenderse, mientras ella se consideraba una mujer inteligente y perspicaz. Esa actitud es característica en muchas víctimas que, aunque en términos generales conocen el concepto de acoso y son familiarizadas con algunos de sus rasgos principales, no consiguen identificar su propia situación con una del acoso sexual y se niegan a aceptar que ya forman parte de la estadística (INMARK 2006: 15). Precisamente el hecho de haberse considerado demasiado fuerte y lúcida como para sufrir este tipo de hostigamiento señala que Nevenka, antes de convertirse en la víctima, compartía la postura de la sociedad que la rodeaba y pensaba que esos casos afectaban siempre al mismo perfil de mujeres inestables. Un papel importante en el desarrollo de su capacidad de identificar su propia situación ha jugado el libro El acoso moral de Marie-France Hirigoyen. Tal y como lo describe el autor, "este libro es la Biblia para comprender lo que ocurre en tales situaciones” (Millás 2013: 101).

Así, al descubrir que siempre vivía en un mundo de ilusiones que se derrumbó debido al trauma producido por el acoso sufrido, Nevenka concluye: "Hay algo que no es como me dicen" (Millás 2013: 117). Durante ese "proceso de extrañamiento", como lo denomina Millás (2013: 28), Nevenka empieza a cuestionar los valores de la educación que ha recibido y entender su dependencia de la figura paternal y los 
escrúpulos morales que le impedían a desarrollar sus propios intereses. De hecho, sus padres eran de mentalidad cerrada, basada en los valores patriarcales y marcada con un fuerte machismo y homofobia. Como tales, influyeron en gran medida en el desarrollo de la personalidad de su hija, lo que resultó ser uno de los factores clave que la convirtió en la víctima del acoso sexual. Una vez apartada de esa filosofía moral, Nevenka empezó a desarrollar su independencia mental y emocional y actuar según sus propios intereses. Esa transformación en su personalidad la ejemplifica el tatuaje de un Piolín que se hizo. Con ese gesto, no sólo pretendía mostrar a los demás que ya había dejado el concepto de la niña ejemplar (el tatuaje en su familia estaba mal visto), sino que también la simbolizaba a ella -siendo un ser "enjaulado" que, aun así, consigue salir bien de cualquier situación de peligro-, y le servía para demostrar a sí misma que era capaz de ganar al alcalde. De modo más general, esta metamorfosis le permitió dejar de identificarse con el sistema de valores de toda la sociedad y recuperar su autonomía.

Este cambio permite el inicio de la segunda transformación, donde la víctima, pasa de un estado de pasividad y sumisión a afrontar el acoso. Así, cuando Nevenka por fin aceptó su realidad, tras muchos meses de padecer estrés emocional y depresión, tras sentimientos de impotencia, ira y baja autoestima, sus ganas de moverse se volvían cada vez más fuertes. Entendió que necesitaba fortalecer inferiormente para ganar esa lucha. Se centró en analizar las causas que provocaron el acoso (tanto aquellas relacionadas directamente con el hostigamiento como las más implícitas), en hacer una cronología de sucesos y buscar las pruebas contra su acosador. Quizá el rasgo más profundo de ese cambio de actitud en Nevenka se refleja en su reacción victoriosa al presentar los motivos de su dimisión en la rueda de prensa: 
Lucas fue testigo de una transformación en Nevenka que no olvidará en su vida. Dice que poco a poco fue dejando de temblar, al tiempo que en su rostro comenzaba a dibujarse una sonrisa de placidez que él no le había visto jamás. Cuanto más se alejaban, más se acentuaba en ella esa sensación de paz interior. (Millás 2013: 16)

Sólo después de leer toda la obra, se hace evidente que el elemento clave en ese cambio de la personalidad de Nevenka era su novio Lucas. Es un personaje que no hace muchas preguntas, no da entrevistas, no cree en las suposiciones y no cae ante las presiones de su alrededor. Lucas es probablemente el único que no necesitaba conocer todos los detalles de la historia para no dudar de Nevenka, quien apoyó todas sus decisiones e inició esa lucha aparentemente absurda junto con ella. Y de ahí su magnitud -es una figura que no se exponía, pero que siempre estaba visible por su grandeza-. El autor mismo reconoce el papel enigmático y sustancial de Lucas: "vi cómo cobraba importancia a medida que pasaban los capítulos sin que él hiciera nada por crecer ni yo por aumentar su tamaño" (Millás 2013: 201).

\section{Las etapas del acoso}

El acoso sexual no se percibe como una situación aislada, más bien presenta un conjunto de conductas que incrementa a medida que aumenta la gravedad y la intensidad del acoso. En casos más graves, el acosador suele desarrollar una relación de confianza con su víctima antes de convertirse en su acosador, por lo que las personas que sufren este tipo de presión muchas veces no son capaces de asumir que están siendo acosadas sexualmente, ya que los ataques vienen de la persona por la que sentían afecto e incluso admiración.

En ese sentido, la personalidad de Ismael Álvarez corresponde a la figura de un acosador. Se caracteriza por una conducta perversa, con tendencias psicopáticas y 
características psicológicas patológicas previas al acoso. De hecho, cuando ocurrió el “caso Nevenka", él rondaba los 50, era viudo (cuando conoció a Nevenka su esposa todavía estaba viva, pero falleció pocos meses después) y tenía dos hijos. Era un hombre con fama de mujeriego, representaba la autoridad y disfrutaba mucho del poder que tenía. Gobernaba con métodos caciquiles y se necesitaba su autorización para realizar cualquier cosa en el pueblo. Su carácter quedó reflejado en una revista que se refería a él con las palabras: "Ismael I, emperador de Ponferrada" (Millás 2013: 23).

Ismael iba acercándose a su víctima de manera sutil, amigable y aparentemente bien intencionada, hasta que, tras una serie de situaciones y apoyándose en su nuevo papel de un hombre viudo, consiguió conmoverla y ganar toda su confianza. Simulaba ser su amigo para obtener la información personal e íntima de su vida, que en el futuro le servirían para controlarla y monitorizarla. Iñaki Piñuel y Zabala considera "la violación de la confianza depositada en la persona" (2001: 140) uno de los aspectos más destructivos del psicoterror. Al principio, Nevenka no se tomaba en serio esas insinuaciones y bromas que venían de su jefe. Además, aunque a momentos interpretaba sus gestos y comentarios como inoportunos, lo dejaba pasar porque venían de su superior y porque muchas situaciones tuvieron lugar en presencia de otras personas. Sin embargo, precisamente ese hecho muestra el carácter de Ismael -es un agresor arrogante, con un nivel de autoestima sobreevaluado, que considera que la mujer es inferior al hombre-. Su matrimonio fue un blindaje necesario para cumplir las normas de la sociedad y llegar a presentar una figura deseable, tanto en su ámbito social como profesional, cuando realmente nunca respetaba a su pareja. No mostró ninguna consideración ni siquiera después de la muerte de su esposa, ya que no paraba con su intención de seducir a la joven concejala. 
Como resultado de tanto acercamiento, finalmente logró conquistarla. Durante el poco tiempo que mantuvieron una relación sentimental, Nevenka era la estrella del Ayuntamiento. Sin embargo, al terminar la relación, empezó a sentir las primeras consecuencias de esa ruptura. El cambio en el trato del alcalde hacia Nevenka de "la mejor concejala" a "esa señorita" se manifestó también en su relación con otros compañeros: "sus negativas producían en él reproches de inestabilidad y un enfriamiento de las relaciones laborales que todo su equipo reproducía de manera mimética" (Millás 2013: 152). La ignoraban, no la informaban sobre los datos relevantes para su trabajo, e incluso la hicieron cambiarse a un despacho de peor calidad. Tal comportamiento de los compañeros es característico en situaciones de acoso y se explica por el miedo que "genera conductas de obediencia, cuando no de sumisión, en la persona atacada, pero también en los compañeros que dejan hacer y que no quieren fijarse en lo que ocurre en su alrededor" (Hirigoyen 1999: 63). Aparte del temor a convertirse ellos mismos en el objeto de represalia, también pueden pensar que la propia víctima ha provocado las situaciones de acoso y que se merece tal trato. De hecho, necesitan creer en la culpabilidad de la víctima para justificar su propia abstinencia en ayudar. Según Piñuel (2001: 100), la mayoría de ellos se convierte en "testigos mudos" que, aunque en muchas ocasiones plenamente conscientes de la injusticia y el acoso que se producen en su entorno, se muestran indiferentes y se mantienen neutrales. Sin embargo, tal actitud los convierte en una parte activa del proceso de estigmatización sistemática de la víctima.

Tal situación hace que la víctima termine convirtiéndose en lo que le reprochan ser (inútil, paranoica, desconfiada e incapaz). Así, Nevenka primero dejó de cuidar de su aspecto físico, iba vestida de negro y llevaba la ropa que le quedaba grande. Esa 
actitud se ve muy característica en mujeres que sufren hostigamiento sexual. Llegan a pensar que su forma de vestir o su comportamiento han provocado los comentarios o gestos inadecuados de su superior, por lo que dejan de preocuparse por su físico, por vergüenza o por sentirse culpable. Con el tiempo se sometió a su agresor, esperando que la intensidad de los ataques disminuyese, hecho que se proyectó también en su estado de salud. Sin embargo, todas las situaciones particulares en las que se produjo algún tipo de hostigamiento ocurrieron paulatinamente, formando parte de la estrategia del alcalde. Así, a medida que ella se volvía más vulnerable, humillada y agotada emocional y profesionalmente, el nivel de acoso ejercido se hacía más grave, hasta llegar a convertirla en un ser totalmente subordinado a su acosador.

\section{La criminalización de la víctima}

Una de las preguntas que muchos personajes se planteaban en el libro, tanto los que conocían a Nevenka como sus desconocidos, fue por qué no se apartó, por qué permitió esa actitud del alcalde si no estaba a gusto. Lo mismo se preguntaba Nevenka, e incluso en un momento llegó a darle la razón a toda aquella multitud que, incapaz de encontrar una respuesta lógica a la pregunta, decidió culpar a la acosada. Incluso los informes de los psicólogos terminaron siendo una prueba para atribuir a la víctima una personalidad conflictiva y una mentalidad inestable. Ese concepto de la criminalización de la víctima está presente en toda la obra y muestra la vía más simple de racionalizar los sucesos, cuando, en realidad, la pregunta estaba equivocada; no debería importar por qué ella no se apartó sino por qué él atacó. 
Destacando este concepto, Millás se sale de los marcos de su novela y señala que se trata de un síndrome muy arraigado en la sociedad que, por defecto, es propensa a culpabilizar a la víctima, considerando que cualquiera persona honrada evitaría fácilmente una situación indecente o de riesgo. Esa postura directamente califica a la víctima de inmoral, la desacredita y la hace responsable de su propio acoso. Así, la víctima termina convirtiéndose en persona non grata, lo que lleva a la marginalización, a la expulsión de la vida laboral y a la destrucción de la imagen pública.

Sin embargo, para entender realmente esa imposibilidad de Nevenka de reaccionar frente a su acosador, es necesario tener en cuenta todas las etapas del acoso que van desarrollándose gradualmente, de manera que se apoderan de ella y la hacen incapaz de detectar lo que sucede. Por ello, su inacción -aparte de ser un método de defensa- es el resultado de la técnica de su acosador, ya que "el primer acto del depredador es paralizar a su víctima para que no se pueda defender" (Millás 2013: 101). Ella misma comprendió lo manipulada que estaba por su jefe, dándose cuenta de que no se diferenciaba mucho de su perro. El animal dependía de ella al igual que ella de Ismael: “con el perro podía hacer lo que quería y siempre estaba ahí para recibir los palos" (Millás 2013: 76).

Otro misterio que se presenta en la mente de la sociedad es la relación consentida que en el principio Nevenka obtuvo con Ismael. ¿Cómo una chica joven de 25 años pudo enamorarse de un hombre que le doblaba la edad? El hecho de que ese hombre, además, era su jefe, hizo que el pueblo la considerara inmoral y mercenaria, y, por tanto, que no mostrara ninguna empatía o comprensión hacia ella. Por eso, muchos buscaban cualquier razón para justificar la conducta del alcalde, de manera que crearon sus propias percepciones sobre la personalidad y el aspecto de Nevenka. Durante los seis 
meses que estuvo de baja, corrían dos noticias sobre el motivo de su desaparición, "que permanecía en Madrid sometida a una cura de desintoxicación de drogas, pero también que había ingresado en una secta” (Millás 2013: 9). El ejemplo de una conocida del autor que llegó a ver a Nevenka en la rueda de prensa "con una minifalda hasta aquí" (Millás 2013: 26), aunque ésta llevaba pantalones, muestra claramente esa necesidad de ver lo que uno esperaba de una joven de poca moral que protagonizó un caso de acoso sexual por su culpa.

Sin embargo, Nevenka inició esa relación porque su subconsciente encontró en Ismael a esa figura de un padre solícito que ella necesitaba. Al principio lo consideraba muy cariñoso y le admiraba por lo que consiguió en la vida. Tal y como lo señala Millás, la figura del alcalde funcionaba como "una prótesis del padre que Nevenka tuvo jamás: un padre sensible y a la vez dotado de gran autoridad” (Millás 2013: 150). De ahí tanto rencor y dolor cuando este segundo "padre" dejó de ser lo que ella imaginaba y empezó a provocarle daño. Se llevó una decepción, ya que volvió a confiar e invertir en una relación que resultó tener repercusiones muy negativas. Por eso cabe preguntarse si, como dice Millás, “al denunciar a Ismael Álvarez no estaba denunciando, no ya a su padre, sino a toda una sociedad a la que había intentado complacer durante años sin ningún resultado" (Millás 2013: 116).

\section{Múltiples capas del acoso}

Aparte del acoso sexual ejercido por el alcalde y el hostigamiento por sus compañeros de trabajo, al poner la denuncia, Nevenka empezó a sufrir agresiones a 
nivel extralaboral. La primera que la atacó fue la prensa. Se interesaba por su vida privada y sus relaciones sentimentales, como si buscara información para convertir a la víctima en culpable. Algunos medios la presentaban incluso como una chica de baja moral y con mucha experiencia en relaciones sentimentales, cuando realmente, sin contar con el alcalde, Nevenka había tenido sólo dos novios. La función de la prensa, en términos generales, era mantener la circulación y mantener al pueblo interesado en la noticia. Por eso intentaba hacer el personaje de Nevenka lo más interesante posible para su público, convirtiéndose en la nueva acosadora de la joven concejala. De ahí el consejo que el Señor Invisible, un personaje misterioso que le posibilitó a Millás el contacto con Nevenka, le dio a la protagonista una vez puesta la denuncia:

En estas cosas no hay término medio, Nevenka. Si das una entrevista, una sola entrevista, te habrás metido en una rueda imposible de detener. Y si entras en el circuito de los programas de televisión de sobremesa, ya no podrás controlar tu imagen. A partir de ese instante, bastará que alguien te saque una foto en un bar, con una copa en la mano, para que circule sobre ti una imagen de frivolidad de la que no podrás defenderte. Durante todo este tiempo, hasta que salga el juicio, y calcula que tardará en salir un año, tienes que llevar una vida de monja. (Millás 2013: 181)

Las capas de acoso siguieron profundizándose durante el juicio, donde el papel central lo tenía el fiscal José Luis García Ancos, que se refería a Nevenka como si fuera acusada y no la víctima: “'por qué usted, que ha pasado este calvario, este sufrimiento, que se le han saltado las lágrimas, por qué usted que no es una empleada de Hipercor que le tocan el trasero y tiene que aguantar por el pan de sus hijos, por qué usted aguantó?” (Millás 2013: 24). Estas palabras tuvieron mucho eco en la prensa española y causaron protestas de muchas organizaciones, de tal medida que el juez tuvo que 
reemplazar al fiscal. Sin embargo, era tarde; ésta y sus otras preguntas inadecuadas hicieron que Nevenka volviera a ser acosada, esta vez por la Justicia.

El hecho de haber ganado el juicio le hizo pensar que podía volver a España y reestablecer su vida con su novio Lucas. Sin embargo, un año después de buscar un trabajo sin ningún resultado, comprendió que esa sociedad biempensante no tenía más remedio que creer que ella se merecía todo lo que le había ocurrido. El escándalo producido por el acoso y el juicio dejaron en su nombre una mancha imposible de quitar, por lo que decidió abandonar definitivamente su tierra e irse a una ciudad al norte de Europa. Por otro lado, Ismael, el agresor, aunque dimitió de su cargo, seguía en Ponferrada y hacía sus negocios sin repercusiones significativas. Esto demuestra que, aunque supuestamente ganó el juicio, Nevenka no dejó de ser incomprendida por toda la sociedad. El autor cierra este círculo de acosadores, ya sean conscientes o inconscientes de sus actos, concluyendo que Nevenka "había sido víctima de su propia cultura, una cultura machista, misógina, brutal en muchos aspectos" (Millás 2013: 25).

\section{Las consecuencias del acoso}

Cuando está sometida a las situaciones del acoso, la víctima pierde la confianza en sus propias capacidades profesionales, sufre mucha presión y se la excluye socialmente. Como consecuencia, se deteriora su estado psicofísico y reduce su eficacia y productividad laboral. Más adelante, esto incluso puede llegar a atribuirse a la personalidad inestable o difícil de la víctima o a su incapacidad profesional, de manera que se trata de, en palabras de Piñuel, un "crimen limpio" (2001: 56), en muchas 
ocasiones difícil de comprobar. Justamente esas acusaciones que se usaron contra Nevenka, junto con el propio acoso, causaron una serie de consecuencias en su estado psicológico, emocional y físico.

La ansiedad que el acoso produjo en Nevenka implica la presencia de un miedo acentuado y continuo, que desencadenó una patología propia del estrés crónico (Camps del Saz et al 1996: 12). Ese estrés crónico implica reacciones psicosomáticas que producen un amplio espectro de efectos negativos sobre el organismo: fisiológicos, cognitivos, psicológicos, sociales y de comportamiento (Del Hoyo Delgado 2004; Piñuel y Zabala 2001). A continuación, se presentan algunas de las reacciones de Nevenka como consecuencia del terror psicológico y sexual que sufrió:

- Consecuencias fisiológicas: estaba pálida, se despistaba a menudo, perdió mucho peso y, tal como lo describe Millás después de su primer encuentro, "parecía una criatura recién salida de un campo de concentración” (Millás 2013: 33).

- Consecuencias cognitivas: se mostraba confusa y sin iniciativa, al principio incluso pensó que estaba loca y que se inventó toda esa serie de acontecimientos.

- Consecuencias psicológicas: perdió la autoestima, sufría ataques de pánico y se mordía las uñas como signo de ansiedad y de nerviosismo.

- Consecuencias sociales: se aislaba del mundo real, se pasaba los días encerrada en casa y, según sus propias palabras "se imaginaba a sí misma como una fortaleza en ruinas” (Millás 2013: 75). 
- Consecuencias de comportamiento: tranquilizaba sus nervios fumando un cigarrillo tras otro y se tomaba tantos ansiolíticos y tranquilizantes en aquella época que nunca ha vuelto a estar bien del estómago.

Además, el apoyo que la víctima recibe de su ámbito familiar y social en situaciones como ésta afecta en gran medida el grado del deterioro psicológico y anímico que sufrirá. Así, si la víctima carece de la comprensión y la solidaridad de estos individuos, incrementará su nivel de estrés y los síntomas que éste provoca (Piñuel y Zabala 2001: 81). En ese sentido, cabe señalar la incomprensión absoluta del padre de Nevenka al enterarse del acoso: "si te gustan los viejos, ¿por qué no subes a la residencia del Imserso?” (Millás 2013: 65). Este comentario, por muy decepcionante que fuera en ese momento, inició su separación de la figura paterna como modelo a seguir.

Como resultado final de la historia, se distinguen dos vías después del acoso: la positiva, donde el cambio en la víctima se realiza como un aprendizaje; y la negativa, que implica la desvalorización. La primera se interpreta observando el personaje de Nevenka desde dentro. Aunque después de ganar el juicio no recibió muchas palabras de solidaridad, Nevenka se sintió fortalecida y recuperó su honor. Tal y como lo señala el autor: "ella había abierto con su actitud un camino del que en un futuro se beneficiarían otras mujeres en una situación semejante a la suya” (Millás 2013: 196). Precisamente por eso, y a pesar de las evidentes consecuencias negativas del acoso, la novela conlleva un mensaje optimista. Millás ha conseguido convertir a su protagonista en una heroína, señalando que en ella sucedió algo extraordinario. Cuando incluso el autor reconoce que le habría recomendado dimitir y dar por terminado el asunto, Nevenka recuperó la fuerza y decidió luchar por su dignidad. Por otra parte, analizando 
el personaje de Nevenka desde fuera, esto es, en relación con su entorno, se observa el efecto negativo de lo ocurrido. A pesar del resultado del juicio, la víctima terminó siendo etiquetada de conflictiva (una persona capaz de denunciar a su jefe por acoso no dejaba una buena imagen en el mercado laboral) y le resultó imposible conseguir un trabajo y rehacer su vida en España. Se fue del país, en búsqueda de esa paz perdida que conllevaba el anonimato y la intimidad.

\section{Conclusión}

Fauquet (2011: 260) señala tres niveles en los que se constituye la ejemplaridad de la obra de Millás: la imagen modélica de Nevenka que ha conseguido superar el estatus de la víctima y denunciar una práctica todavía tabú en la sociedad de España, la investigación realizada y el compromiso ético del narrador-personaje y con él -del autor- y la novela como un alegato de un sistema fundado en el machismo y de la manipulación de la realidad a través de un discurso político y mediático. Así, además de denunciar el sistema español y la esfera política del país, Millás denuncia la distorsión de la información y el tratamiento parcial de la prensa, especialmente de la prensa local: "No leí ningún editorial sobre el caso, quizá porque a ningún periódico le pareció extraño o enfermizo que la víctima se hubiera exiliado mientras el verdugo leía el pregón de las fiestas en su pueblo" (2013: 199).

Dicho en términos más generales, la novela trata el tema del machismo en el siglo XXI, reflejado en la figura de un superior que considera que la mujer es inferior al hombre y que, aprovechándose del poder que le posibilita su posición, acosa a sus 
subordinadas. De ahí que el personaje de Ismael Álvarez represente el prototipo de esa figura, teniendo características de un amo, antes que de un jefe. Así se llega a uno de los grandes mitos sexistas: la palabra de la mujer no tiene valor. Ella debe someterse, él decidir.

La finalidad didáctica de la obra se refleja en la intención del autor de describir los mecanismos y las consecuencias del acoso a través de un caso concreto. De hecho, aunque el concepto del acoso sexual se ha popularizado en las últimas décadas en la cultura occidental y es criticado públicamente, suele ser consentido en la práctica. Todavía se conocen pocos casos acaecidos y las víctimas realmente no cuentan con un apoyo institucional. Al contrario, suelen ser los acosadores quienes, en caso de denuncia, consiguen el apoyo de sus autoridades. El autor señala, también, la falta de información y poco desarrollo de la consciencia de las mujeres acosadas, lo que hace que ellas no identifiquen bien la situación por la que están pasando y desconozcan sus derechos para defenderse.

\section{Referencias bibliográficas}

Alemany Gómez, Carme et al. 2001. El acoso sexual en los lugares de trabajo. Madrid: Instituto de la Mujer, Ministerio de Trabajo y Asuntos Sociales.

Amar Sánchez, Ana María. 1990. "La ficción del testimonio". Revista Iberoamericana, 151: 447-461.

1992. El relato de los hechos. Rodolfo Walsh: testimonio y escritura. Rosario: Beatriz Viterbo Editora.

Camps del Saz, Pilar et al. 1996. "Hostigamiento psicológico en el trabajo: el mobbing". Salud y Trabajo. Ministerio de Trabajo e inmigración: Instituto Nacional de Seguridad e Higiene en el Trabajo, 118: 10-14. 
Casas Cáncer, Elisenda. 2011. Acoso sexual en el trabajo. Mutua de Accidentes de Trabajo y Enfermedades Profesionales de la Seguridad Social (ASEPEYO), 151: 1-26. http://www.navarra.es/NR/rdonlyres/1D689354-F896-4A62-85FB-E3C8F3 CC6DFE/153599/AsepeyoAcoso_Sexual.pdf [18 de enero de 2018].

Del Hoyo Delgado, María Ángeles. 2004. Estrés laboral. Madrid: Instituto Nacional de Seguridad e Higiene en el Trabajo.

Díaz Descalzo, María Carmen. 2003. "El acoso sexual en el trabajo". Mujer y Trabajo. Coord. Esther Ruíz Pérez. Albacete: Editorial Bomarzo. 179-203.

Equal Employment Opportunity Commission, Guidelines on Discrimination because of Sex. Code of Federal Regulations, Title 29. Part 1604.11. Published in 45 FR 74677, Nov. 10, 1980, as amended at 64 FR 58334, Oct. 29, 1999. https://www.gpo.gov/fdsys/pkg/CFR-2007-title29-vol4/xml/CFR-2007-title29vol4-sec1604-11.xml [22 de enero de 2018].

Fauquet, Isabelle. 2011. "Trayectorias ejemplares en Hay algo que no es como me dicen. Caso de Nevenka Fernández contra la realidad, de Juan José Millás”. La ejemplaridad en la narrativa española contemporánea (1950-2010). Eds. Amélie Florenchie e Isabelle Touton. Madrid: Iberoameticana, Frankfurt am Main: Vervuert. 259-277.

González De Rivera, José Luis. 2002. El maltrato psicológico: cómo defenderse del mobbing y otras formas de acoso. Madrid: Espasa Calpe.

Hamon, Philippe. 1984. Text et idéologie. Paris: Presses Universitaires de France.

Hirigoyen, Marie-France. 1999. El acoso moral. El maltrato psicológico en la vida cotidiana. Barcelona: Paidós Ibérica.

INMARK Estudios y Estrategias. 2006. El acoso sexual a las mujeres en el ámbito laboral. Madrid: Instituto de la Mujer. Ministerio de Trabajo y Asuntos Sociales.

http://158.109.129.18/centreantigona/izquierda/acoso\%20sexual\%20en\%20Espan a.pdf [ 2 de febrero de 2018].

Ley Orgánica 10/1995, de 23 de noviembre, del Código Penal. Boletín Oficial del Estado, núm. 281, de 24 de noviembre de 1995. Última modificación: 28 de abril de 2015. https://www.boe.es/buscar/pdf/1995/BOE-A-1995-25444consolidado.pdf [2 de febrero de 2018].

Millás, Juan José. 2013 [2004]. Hay algo que no es como me dicen. El caso de Nevenka Fernández contra la realidad. Barcelona: Seix Barral.

Moreno Jiménez, Bernardo y Carmen Báez León. 2010. Factores y riesgos psicosociales, formas, consecuencias, medidas y buenas prácticas. Madrid: Instituto Nacional de Seguridad e Higiene en el Trabajo y Universidad Autónoma de Madrid.

Pérez Guardo, Rocío. 2012. "Las limitaciones en la cuantificación del acoso sexual laboral en España". Athenea Digital, $12 \quad$ (2): 199-219. 
https://atheneadigital.net/article/viewFile/v12-n2-perez-2/1022-pdf-es $\left[\begin{array}{ll}2 & \text { de }\end{array}\right.$ febrero de 2018].

Piñuel y Zabala, Iñaki. 2001. Mobbing. Como sobrevivir al acoso psicológico en el trabajo. Santander: Sal Terrae.

Sánchez Zapatero, Javier. 2011. "Escritura autobiográfica y traumas colectivos: de la experiencia personal al compromiso universal". Revista de Literatura, juliodiciembre, LXXIII, 146: 379-406. 